\title{
Del discurso del desarrollo a la visión territorial sostenible
}

From the speech of development to the sustainable spatial vision

Franz Gutiérrez Rey ${ }^{1}$

\section{Resumen}

En este artículo se analiza el contrasentido del desarrollo en la modernidad, sus implicaciones y la importancia de develar, resignificar o deconstruir el discurso del desarrollo y su presunción de universalidad en los países del tercer mundo, y en especial en América Latina, donde comienzan a florecer nuevas visiones del desarrollo territorializadas y sostenibles en oposición al pensamiento desarrollista occidental, y en las cuales la geografía y los geógrafos tienen la oportunidad de aportar mediante sus fundamentos, competencias y saberes reconocidos. Por tanto, la reinterpretación de la modernidad en América Latina se convierte en un ejercicio fundamental y esclarecedor, para abandonar los esquemas mentales del desarrollismo colonial, y construir la visión territorial sostenible para un buen vivir y convivir como especificidad posmoderna en América Latina.

Palabras clave: Discurso del desarrollo, desarrollo territorial, desarrollo sostenible, modernidad, geografía.

1 Geógrafo, Magíster en Geografía con énfasis en Ordenamiento Territorial. Filiación Institucional: Docente Universidad Pedagógica y Tecnológica de Colombia (UPTC); Candidato a Doctor (UPTC-IGAC); Director Grupo de Investigación Ordenamiento Ambiental del Territorio (OAT). País: Colombia. Correo electrónico: franz@geordena.com - franz.gutierrez@uptc.edu.co-http:// www.geordena.com 


\section{Abstract}

This article analyzes the contradiction in modern development, its implications and the importance of uncovering, to redefine or deconstruct the discourse of development and its assumption of universality in the third world countries, especially in Latin America where new visions of sustainable territorial development in opposition to Western development thinking begin to bloom, and in which geography and geographers have the opportunity to contribute through their foundations, skills and knowledge. Therefore, the reinterpretation of modernity in Latin America becomes a fundamental and enlightening exercise to abandon the colonial mindset of developmentalism in building a sustainable spatial vision for a good life and specifically in postmodern Latin America.

Keywords: Speech development, regional development, sustainable development, modernity, geography. 


\section{Introducción}

La cultura del desarrollo occidental se ha establecido como un modelo ideal por alcanzar, convirtiéndose en la realidad del imaginario social y en un concepto central que ha orientado el sentido y la direccionalidad de la actividad de las personas en la modernidad, y en un discurso que estructura y reproduce las formas de pensamiento de occidente. Este discurso del desarrollo crea un dominio del pensamiento y de la acción con un origen histórico y geográfico particular, un espacio en el ámbito político y académico, unos actores que contribuyen a su construcción, difusión y consolidación, y sobre todo una gran influencia en la cultura y vida cotidiana de los pueblos (Sunkel \& Paz, 1971, citados por Múnera, 2007, p. 12).

Los países latinoamericanos del llamado "tercer mundo" dependiente, heredan el discurso e ideología del desarrollo del "primer mundo", con las infortunadas y demostrables consecuencias de su aplicación hoy día, e intentan sobre la misma lógica encontrar la vía para el desarrollo sostenible.

Se ha cargado históricamente con el estigma del desarrollo desigual e intencionado y todos sus epítetos de poder desde los tiempos de la Conquista y la Colonia hasta nuestros días, convirtiéndose en la realidad colonizada por su discurso y que desde comienzos de la segunda posguerra hasta hoy, se sigue en la tarea de "des-subdesarrollarnos".
Así, en la tarea de salir del subdesarrollo van más de sesenta años y no se ha logrado el desarrollo de la misma manera o con igual intensidad como se había propuesto por el modelo occidental, pues actualmente los países se caracterizan por el énfasis en el crecimiento económico y prescinden generalmente de las otras dimensiones territoriales que hacen parte esencial en el logro de una buena vida o de un buen vivir y convivir.

De esta manera, la concepción del desarrollo que prevalece se considera que "no es un hecho objetivo, ni natural, sino que es básicamente una construcción social, un concepto, al cual se le han dado contenidos particulares" y que "como construcción social, es posible deshacerla, deconstruirla y por ende reconstruirla de manera diferente" (Múnera, 2007, p. 26), en beneficio de las comunidades, proponiendo nuevas visiones de vida alternativas, que no necesariamente están basadas en la concepción clásica del desarrollo occidental.

En este sentido, hoy en día en América Latina surgen y se renuevan conceptos de la premodernidad y de la modernidad, en la búsqueda de una visión sobre el desarrollo o de vida más justa, lo que implica la revisión de la sostenibilidad en la teoría neoliberal y el reconocimiento de las diferentes culturas, sus planes de vida y visiones propias de sus territorios ${ }^{2}$.

2 Formas de vida, de organización social y económica, y formas de manejo de sus recursos y territorios diferentes 
Con base en lo anterior, en el artículo se propone de manera general una visión del desarrollo sostenible a partir de la deconstrucción del discurso del desarrollo y se expone el ámbito geográfico y el papel de la geografía en este campo de las utopías.

\section{Construcciones conceptuales}

Dependiendo de los imaginarios colectivos, de las representaciones mentales o de los conceptos con que una población humana mediatiza su relación con el mundo, las sociedades humanas construyen sus herramientas conceptuales (o de lectura), organizacionales y materiales para abordar una problemática determinada; es decir, sus políticas, instituciones, programas, acciones e inversiones. [...] Estas construcciones conceptuales son herramientas típicamente humanas, producidas en un contexto espacio-temporal y culturalmente definido que las condiciona. [...] Esto ha venido sucediendo con los diferentes paradigmas1 (González, 2006, p. 17-18).

Así, "las palabras y los conceptos surgen de las condiciones particulares en que, como herramientas, son producidas por los seres humanos, [...] con fines interpretativos y corresponden a momentos culturales, con condicionantes ideológicos, políticos, sociales e históricos”

a las hegemónicas.
(Vidart, 1986, citado por González, 2007, p. 25-26).

\section{Un punto de partida}

A comienzos del siglo XVII, la obra de Descartes pone los cimientos de la ciencia y la filosofía modernas (occidental). René Descartes (1596-1650) en su famoso texto El Discurso del Método, concibe el pensamiento humano como el fundamento último e inevitable de toda verdad sobre el mundo; primero está la idea y después, la materia. "Pienso luego existo", "cogito ergo sum", "yo pienso luego soy", en cualquiera de estas formas es una de las proposiciones más conocidas de la filosofía y es un elemento esencial del llamado racionalismo occidental. Lo anterior implica la separación entre mente y cuerpo, espíritu y naturaleza.

Plantea González (2006, p. 36-37), que esta separación "crea una ruptura entre el mundo natural y el mundo humano"; y en este sentido se le "da la espalda a la naturaleza y se le atribuye al sujeto humano el poder de dominio sobre el mundo natural". Por tanto "El humanismo occidental se configura prescindiendo de lo natural y construyendo un sujeto racional, sin cuerpo; una mente sin cuerpo, una cultura sin naturaleza".

De esta manera, la modernidad que entra en escena a partir del siglo XVI en la cultura occidental, distancia al hombre (sociedad-cultura) cada vez más de su entorno natural y construye un modo 
de ser social y de saber, caracterizados por la sectorización y especialización que separan procesos sociales y naturales, perdiendo la visión holística; aunque logra un gran avance en el conocimiento particular y específico de los fenómenos, carece de una perspectiva articuladora que fortalezca el saber, mediante el potencial explicativo de los contextos (González, 2006).

Asimismo, el paradigma de la modernidad constituye la base de la lectura de la relación sociedad-naturaleza, clave para entender los conceptos del desarrollo y su constante adjetivación ${ }^{3}$.

Parte de una idea central, a saber: la construcción de una noción de sujeto autoconsciente (el ser humano), que a su turno, se opone a un objeto externo (la naturaleza).

Esta separación entre ser humano y naturaleza, promovida en su origen moderno por la escisión cartesiana entre espíritu y cuerpo, ha tenido profundas implicaciones en la comprensión de la relación sociedad-naturaleza. Y como hecho intelectual, se manifiesta de forma material en la destrucción de la na-

Se ha desatado una verdadera polisemia en torno al término de desarrollo, es decir, una multiplicidad de significados, cada uno de los cuales reclama identidad única con relación al adjetivo con que se acompaña el sustantivo "desarrollo". Así se asiste a una verdadera proliferación de "desarrollos": desarrollo territorial, desarrollo regional, desarrollo local, desarrollo endógeno, desarrollo sostenible, desarrollo sustentable, desarrollo humano, desarrollo humano sostenible, desarrollo alternativo, desarrollo a escala humana, desarrollo de bajo impacto y, en términos de su dinámica, desarrollo "de abajo-arriba" o su contrapartida, "del centro-abajo", "otro desarrollo", "desarrollo participativo", "desarrollo socialista", entre otros más. turaleza, generada por el desarrollo del capitalismo y su expansión planetaria (González, 2006, p. 19).

Es decir, que la apropiación de la naturaleza, con fines productivos, basada y justificada en el desarrollo científico y técnico, así como en la superioridad humana sobre los demás seres conduce a la destrucción del planeta paulatinamente, y amenaza la supervivencia humana.

Esta visión dominante en pleno siglo XXI corresponde aún a la división entre naturaleza y sociedad, propia de la cosmovisión de la modernidad, base del modelo de desarrollo actual, sustentado en el enfoque mecanicista de la naturaleza, que desde la economía se mercantiliza ${ }^{4}$ (paradigma del desarrollo en su enfoque clásico).

Por tal razón, en el marco del desarrollo actual las acciones que se emprenden para la solución de los problemas socioambientales, siguen estando circunscritas a la generación de normas (enfoque curativo), de incentivos para promover conductas deseables o al campo tecnológico ${ }^{5}$ (lectura reduccionista). Estas acciones (remediales y puntuales), se ubican y apoyan en campos disciplinares como el biológico, tecnológico, económico, pedagógico o jurídico, entre otros. Los problemas de esta manera no son tratados desde una perspectiva éticopolítica, lo que impide clarificar el horizon-

4 Dominio ideológico de la visión de la economía neoclásica, que ha penetrado los ámbitos de la política y la ética (González \& Galindo, 1999).

5 Por ejemplo, para disminuir la pobreza, evitar la destrucción de recursos o mitigar los riesgos frente a amenazas naturales. 
te en sentido adecuado a la magnitud de la problemática, y a lo que ella significa como cuestionamiento crítico a los fundamentos paradigmáticos de la cultura occidental (González, 2006, p. 26,28).

\section{El desarrollo}

En Latinoamérica, la cultura del desarrollo occidental se establece como un modelo por lograr por los distintos pueblos que entran en contacto con ella. Luis Guillermo Lumbreras (1992) citado por Múnera (2007), expone esta situación de la siguiente manera:

Europa descubrió América [...] y una fácil racionalidad evolucionista nos clasificó como iguales a los primigenios habitantes bárbaros o salvajes europeos, considerando por ello que el nivel de desarrollo por ellos alcanzado era superior a los nuestros [...]. Comenzamos a caminar juntos con una neta ubicación histórica diferenciada, donde nosotros éramos sus contemporáneos primitivos; nuestro futuro tenía la tarea de alcanzar las fases históricas superadas por ellos. Esta concepción la hemos hecho nuestra a lo largo de estos cinco siglos, con graves conflictos [...] Quienes asumen como suya esta ubicación histórica de nuestros pueblos consideran que el paradigma occidental es una meta posible y deseable, con prescindencia de lo ocurrido en nuestra etapa de matriz colonial [...] quienes com- parten esta concepción pasan por alto que no somos países nuevos ni recién llegados y que precisamente la concepción colonial nos impidió avanzar sobre nuestros pies con un proyecto propio. (p. 14).

Escobar (2007) argumenta en cuanto al influjo de la cultura del desarrollo occidental, que:

Dicho francamente, mientras Europa se alimentaba de sus colonias durante el siglo XIX, el Primer Mundo de hoy se alimenta del Tercer Mundo". [...] El desarrollo debe ser visto como un régimen de representación, como una invención, que resultó de la historia de la posguerra y que, desde sus inicios, moldeó ineluctablemente toda posible percepción de la realidad y la acción social de los países que desde entonces se conocen como subdesarrollados. [...] Basta una mirada superficial a los paisajes biofísicos, económicos y culturales de la mayor parte del Tercer Mundo para darse cuenta de que el desarrollo está en crisis, y que la violencia, pobreza y deterioro social y ambiental crecientes son el resultado de cincuenta años de recetas de crecimiento económico, "ajustes estructurales", macroproyectos sin evaluación de impacto, endeudamiento perpetuo, y marginamiento de la mayoría de la población de los procesos de pensamiento y decisión sobre la práctica social. (p. 11-13, 148) 
Y Orlando Fals Borda, en el prólogo del libro de Escobar (2007), sobre el tema señala:

Confrontar el discurso del desarrollo, no aceptarlo de rutina como la panacea del punto IV propuesto por el presidente Harry Truman en 1949, es una necesidad vital para nosotros los del mundo dependiente. Vital, porque en ello se juegan la autonomía, la personalidad y la cultura, las bases productivas y la visión del mundo que nos han dado el hálito de vida como seres humanos y pueblos dignos de respeto y de un mejor futuro. La ideología del desarrollismo demuestra a diario las nefastas consecuencias de su aplicación en el Tercer mundo. [...] Los que en verdad se han venido desarrollando, enriqueciendo y acumulando poder, han sido los que en este desigual juego se habían situado desde antes como los más privilegiados de la estructura económica, social y política existente; ni los pobres, ni los desposeídos por las injusticias del sistema capitalista se han desarrollado de la misma manera o la misma intensidad como se había postulado. [...], hoy nuestros países se encuentran al borde del desierto ecológico y del infierno explosivo de la miseria de las mayorías. Además del servilismo mimético resultante amenaza nuestras raíces históricas y culturales. [...] El posmodernismo es una categoría elusiva para nosotros que no nos hemos modernizado suficientemente, y es discutible que nos 'modernicemos' ahora a la europea.

Así, se ha cargado históricamente con el estigma del desarrollo desigual intencionado y todos sus epítetos de poder, desde los tiempos de la Conquista y la Colonia (primitivos, primigenios habitantes, salvajes, naturales, bárbaros, incultos, incivilizados, indios) hasta nuestros días (subdesarrollados, tercermundistas, pobres y del sur). El desarrollo se convirtió en realidad en el imaginario social (la realidad fue colonizada por el discurso del desarrollo). Seguimos hoy día desde comienzos de la segunda posguerra en la tarea de "des-subdesarrollarnos".

En la modernidad, el concepto de desarrollo se confunde con el concepto de crecimiento, y muy relacionada con la noción de crecimiento aparece la de progreso, que, simultáneamente, se asocia a la de desarrollo. Hablar de desarrollo, crecimiento económico y progreso, es lo mismo.

La visión mesiánica de progreso se instala basada en la idea de que la supremacía de la razón, unida al descubrimiento de las leyes naturales, mediados por un riguroso método científico, independizaría al hombre para gobernar su destino como mito incuestionable de la sociedad occidental (Bury, 1971). Con base en estas ideas de desarrollo y progreso, se aniquilan culturas y se justifica la destrucción de ecosistemas ${ }^{6}$.

El desarrollo como formación discursiva da origen a un aparato eficiente que relaciona sistemáticamente las 
De esta manera, la concepción de desarrollo que surge de la modernidad, fundada en la idea de progreso propia de la Ilustración como pensamiento universal, ha negado en su aplicación las posibilidades de potenciar las dinámicas y el desenvolvimiento de los patrimonios naturales y culturales de pueblos diferentes a la cultura occidental.

Porto-Gonçalves (2009) enfatiza sobre el particular:

Lo que se critica no es la idea de pensamiento universal, pero, sí, la idea de que hay uno y solamente un pensamiento universal, aquel producido a partir de una provincia específica del mundo, Europa y, sobre todo, a partir de la segunda mitad del siglo XVIII. (p. 122)

Y Múnera (2007), precisa:

Entre las premisas del discurso del desarrollo, que estructuran las formas de conocimiento de occidente, se encuentra la dependencia del progreso social, cultural y político al desarrollo material. Así mismo se plantea la solución de la pobreza en el crecimiento económico del desarrollo; estos presupuestos

formas de conocimiento con las técnicas de poder. La predominancia de este sistema de conocimiento en Occidente ha dictaminado el marginamiento y descalificación de los conocimientos no occidentales (Escobar, 1994). De hecho, el discurso del desarrollo fortalece las relaciones de poder de los países del Norte frente a los países del Sur y permite que los primeros definan y determinen las acciones que deben realizar los segundos (Múnera, 2007) en la perpetuación de la idea hegemónica de la superioridad occidental. adquieren la categoría de verdades universales, evidentes y necesarias, es decir se convierten en paradigmas que orientan el destino de los pueblos. [...] El discurso del desarrollo no solo configura conceptos, enunciados y estrategias (teorías), sino que también establece ámbitos de poder que se materializaron en organismos y/o instituciones en los distintos contextos (Múnera, 2007, p. 29).

Estas instituciones desarrollan conjuntamente programas en las áreas de actividad económica, ambiental y social, con el propósito de crear y garantizar el orden internacional.

Explicado lo anterior, para América Latina la contradicción entre desarrollados (dominadores) y no desarrollados (dominados) sigue vigente, por tanto entender el desarrollo desde la visión del no desarrollo y la dominación es entender las causas que no han permitido el desenvolvimiento de nuestras culturas o impiden la construcción de un desarrollo propio expresados en términos de un "buen vivir y convivir"

\footnotetext{
El buen vivir y convivir, es: un camino propio; una guía para un nuevo modelo de sociedad; un horizonte compartido en el territorio para la cultura de la vida; estar y sentirse bien en armonía con la sociedad y la naturaleza; vivir en equilibrio con lo que nos rodea; el encuentro entre pueblos y comunidades; valorar nuestra historia, nuestra música, nuestra vestimenta, nuestra cultura, nuestro idioma, nuestros recursos naturales, recuperar todo lo nuestro y volver a ser lo que fuimos; vivir bien entre nosotros (no se puede vivir bien, si los demás viven mal); una convivencia comunitaria, con interculturalidad y sin asimetrías de poder; no aspirar a vivir mejor que los otros. No es: un modelo capitalista ni socialista (paradigmas extremos propuestos por Occidente, donde el bienestar del ser humano es lo
} 
Todo lo anterior denota que no es posible pensar en un desarrollo que separe sociedad, cultura, economía y naturaleza. "El reto está en recuperar o construir una nueva epistemología, que armonice el sujeto y el objeto, el mundo natural y el social, creando belleza y paz" (Serres, 1991).

Recientemente las interpretaciones del desarrollo que provienen del swahili africano, del maya guatemalteco, que lo equiparan con la interesante idea de "despertar con acción”, del Quechua "qhapaj" (gente que vive bien), que representa el bienestar que no es el económico, del Aymara "qamiris" (personas que viven bien), de los Guaraniés "iyambaes" (personas que se mueven en armonía con la naturaleza) y "teko kavi" (vida buena) o del quechua ecuatoriano "sumak kawsay" (vida plena), que expresa la idea de una vida no mejor que la de otros, ni en continuo desvivir por mejorarla, sino simplemente buena y el "alli kawsay" (buen vivir), o del aymara boliviano "suma qamaña" que introduce el elemento comunitario "buen convivir", toman importancia por cuanto en la visión indígena latinoamericana no existe el concepto de desarrollo como expresión de un estado anterior (inferior) y otro posterior (superior), es decir de subdesarrollo y desarrollo, y tampoco existe el concepto de riqueza y pobreza determinados por la acumulación y carencia de bienes materiales.

más importante, sin tomar en cuenta las otras formas de existencia); un mejor vivir o vivir mejor, mejor estar o estar mejor, bien estar o estar bien y no se trata de salir de la crisis del capitalismo, sino de salir del capitalismo en crisis para lograr verdaderamente "vivir bien" (Farah \& Vasapollo, 2011; Huanacuni, 2010).
Lo anterior no significa segregación, diferencia, fragmentación, anonimato e individualidad entre otros muchos más, los cuales han sido el resultado para el tercer mundo y América Latina en la óptica y aplicación de la visión del desarrollo occidental. En este contexto, el desarrollo sostenible cobra sentido y puede convertirse en una propuesta ética y política frente al modelo de sociedad propuesto por el desarrollo occidental.

A pesar de la aceptación de la finitud de los recursos y la crisis del modelo occidental que en su discurso cambia el significado que implicaba "el uso sostenible de los recursos vivientes", es decir la salud de la naturaleza, la perduración de esta, por el de la perspectiva mundial de la "salud del desarrollo y la perdurabilidad de éste" (Sachs, 1996), proclama ahora por "la conservación del desarrollo" y no tanto por "la conservación de la naturaleza". El énfasis pasa de la "protección de la naturaleza" a la "protección de la productividad de los recursos naturales para el uso económico". Se reinterpreta la naturaleza como capital, al igual que las personas. Es decir, posa de sostenible, dejando de lado las otras dimensiones del territorio que lo hacen posible.

Vista de esta manera, la visión territorial sostenible supera la perspectiva economicista o productivista del desarrollo expresada en concepción limitada del crecimiento económico y la conservación o preservación del medio ambiente y los recursos naturales, por cuanto la noción de sostenibilidad 
involucra estructuralmente además de los sistemas económico y ambiental, el social, cultural y político institucional (Martínez, 2005; Gutiérrez, 2004, 2010).

La gran crisis no es ecológica sino política, venimos a vivir bien y felices, no a trabajar para consumir, la ciencia y la tecnología deben estar al servicio de las necesidades de las comunidades y no a crear necesidades para ellas y satisfacer la competencia y el mercado en beneficio de unos pocos. Se debe revisar nuestra forma de vivir, cambiar la cultura de la globalización, volver a la interculturalidad y el territorio.

Se precisa por tanto, la construcción de una visión del desarrollo que opere partiendo de una nueva lectura comprensiva e integral de los fenómenos, pero que también se manifieste en una nueva propuesta ética y política que bien podría ser la del desarrollo sostenible, o mejor, de una vida sostenible (VS).

\section{El desarrollo sostenible}

Encontrar la fórmula que permita un desarrollo sostenible territorializado ${ }^{8}$, es decir, la articulación y equilibrio entre las estructuras y los elementos sociales, económicos, ambientales y político institucionales sobre los territorios de forma

8 Visión geográfica del desarrollo que implica incorporar como un conjunto articulado, organizado, ordenado y equilibrado las dimensiones social, natural, económica y político-institucional en las acciones y decisiones (gestión territorial), garantizando la apropiación y permanencia del territorio en beneficio de sus moradores. ordenada ${ }^{9}$, es algo que solo se podrá lograr deshaciendo los desenfoques modernos y desarrollando una nueva visión a partir de este y donde los principios se basen en: la unidad de la naturaleza (mente-cuerpo y cultura-naturaleza); el diálogo entre las ciencias (socialesnaturales); el pensamiento complejo ${ }^{10}$; la ética y la política para la construcción de un modelo de vida sostenible ${ }^{11}$; la gestión pública y la expresión territorial de lo anterior reflejada en un paisaje armónico $^{12}$ (Figura 1).

Un nuevo modelo de vida es la discusión del presente y para esto habrá que buscar salidas coherentes y posibles, construyendo un marco que ayude a la superación de la división entre sociedad, cultura, naturaleza y economía propia de la modernidad; el sujeto debe estar inmerso en el objeto (mundo-naturaleza). En este contexto, el desarrollo sostenible aparece como una propuesta ética y política ${ }^{13}$,

9 Sometidos a una cierta lógica en su distribución y organización e interrelacionados entre sí, funcionalmente, a diversas escalas jerarquizadas, que formalizan unas determinadas estructuras territoriales cambiantes en el tiempo (Méndez, 1988).

10 Este nuevo paradigma (trans-moderno) permite fundamentar los nuevos enfoques sobre el desarrollo que se están construyendo entendidos como una construcción sociocultural múltiple, histórica, cultural y territorialmente determinada (Múnera, 2007).

11 Ambientalmente sana, socialmente equitativa, económicamente factible, cultural y política e institucionalmente reconocida, aceptada y viable en todo sentido.

12 Campo de lectura de las relaciones de poder determinadas, de sus pugnas y soluciones.

13 Esto significa revisar el tipo de propuesta de cultura y sociedad que subyace en la actual forma del ser social y a los presupuestos filosóficos y éticos que la orientan, e igualmente al conocimiento científico que permite su implementación. La ciencia y la tecnología que hacen posible este tipo de sociedad no se pueden separar de los presupuestos éticos ni de las formas políticas que también 
frente a un modelo de sociedad productivista, consumista, individualizada y competitiva generada en la modernidad; modelo neoliberal (González, 2006).

\subsection{Dimensiones}

De acuerdo con el planteamiento conceptual, el desarrollo sostenible (DS) se concibe y propone a partir de cuatro dimensiones: sociocultural, económica, ambiental y político institucional, integradas y en equilibrio desde una perspectiva geográfica (Figura 1 y Tabla 1), en razón a la imposibilidad del sistema de producción capitalista para lograr un desarrollo socialmente equitativo y justo, económicamente igualitario, ambientalmente sostenible y armónico, territorialmente cohesionado, culturalmente aceptado y política e institucionalmente respaldado y protegido.

A la propuesta de dimensiones del desarrollo sostenible (triada o trívium) del informe Brundtland, se integra la dimensión político institucional, por cuanto se considera que de esta dimensión depende la política y gestión del desarrollo sostenible como visión fundante de un Estado

La Figura 1 y la Tabla 1, ilustran las dimensiones y componentes objetivo del desarrollo sostenible que, a su vez, son el objeto de las políticas públicas y la ordenación del territorio en la visión propuesta, en la cual en lo social prima la equidad y la justicia social y territorial;

hacen posible su realización (González, 2006). La técnica no es neutral, está cargada de ideología y es ante todo un proceso político (Ardila, 2011). en lo cultural, la identidad, el arraigo y la pertenencia territorial; en lo económico, la igualdad social y territorial, en lo ambiental, la sostenibilidad y armonía ambiental y territorial, en lo político institucional, la gobernabilidad y la cohesión social y territorial para un buen vivir y convivir como fin último del desarrollo sostenible.

Algunos podrían pensar (generalmente no geógrafos) en cinco pilares o dimensiones de desarrollo sostenible al incluirse la dimensión espacial o territorial en la propuesta, pero se considera que esta está inmersa, implícita y siempre presente en la concepción y gestión de desarrollo sostenible, por tanto se propone hablar de quadrivium o cuadriga del desarrollo sostenible como pilares o dimensiones territorializadas de este.

Desde la perspectiva geográfica en esta concepción, la base o soporte del desarrollo sostenible es el territorio expresado en la territorialidad ${ }^{14}$, territorialización ${ }^{15}$ y racionalización ${ }^{16}$ de las políticas que inciden o repercuten en este. El desarrollo

14 La territorialidad del desarrollo implica vincular las cualidades geográficas del territorio al desarrollo sostenible. "De este modo, la gestión del desarrollo sostenible se realiza en espacios concretos con características geográficas específicas que hay que conocer adecuadamente para que las políticas, normas, planes y acciones sean pertinentes y efectivos" (Massiris, 2012, p. 85).

15 Entendido como desarrollo territorializado, es decir, la construcción, aplicación y gestión de las políticas de desarrollo en el contexto territorial específico y desde este (reciprocidad), buscando siempre el equilibrio al interior de la dimensión y entre las dimensiones de la cuadriga por medio de sus componentes.

16 Referente a la racionalidad de las políticas, normas 0 conceptos y a la localización más racional de lo público (instalaciones e infraestructura), en beneficio de la población (equilibrio, equidad y justicia territorial). 
Figura 1. Quatrivium o cuadriga del desarrollo sostenible, componentes objetivo e intersecciones.

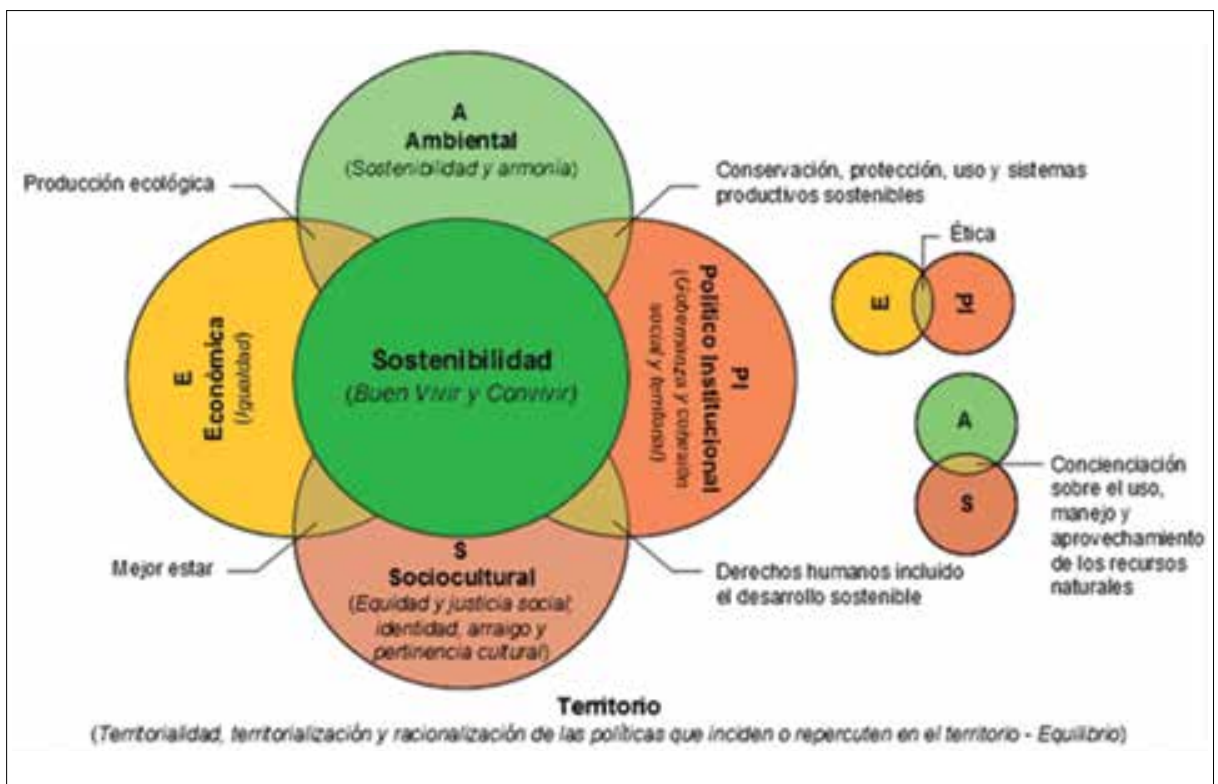

Fuente: Gutiérrez (2010).

Tabla 1. Dimensiones territorializadas del desarrollo sostenible.

\begin{tabular}{|c|c|}
\hline DIMENSIÓN & COMPONENTES OBJETIVO \\
\hline SOCIAL & Equidad social y territorial, y justicia social y territorial \\
\hline CULTURAL & Identidad, arraigo y pertenencia territorial \\
\hline ECONÓMICA & Igualdad social y territorial \\
\hline AMBIENTAL & Sostenibilidad y armonía ambiental y territorial \\
\hline $\begin{array}{c}\text { POLÍTICO } \\
\text { INSTITUCIONAL }\end{array}$ & Gobernanza y cohesión social y territorial \\
\hline
\end{tabular}

Fuente: Elaboración propia. 
sostenible no puede seguir pensándose sin la base territorial que lo integra ${ }^{17}$.

\subsubsection{Significado}

De acuerdo con lo planteado anteriormente, desarrollo sostenible significa:

a) Un nuevo modelo de vida opuesto y crítico al carácter hegemónico y neoliberal del desarrollo imperante.

b) La superación de la división entre cultura-naturaleza-sociedad-economía, propia de la modernidad.

c) Una propuesta ética y política frente a un modelo de sociedad productivista, consumista, centralizadora, competitiva y autodestructiva, generada por la modernidad.

d) La reorientación del sentido y la direccionalidad de la actividad económica y social en la cultura occidental creada con la modernidad.

e) Equidad territorial para el buen vi$v{ }^{18}{ }^{8}$, como garantía de permanencia

17 El territorio no puede concebirse para el desarrollo sostenible solamente como una base de demarcación para la actuación, sin que los contenidos de dicho espacio se consideren en la determinación de sus acciones; o como en la perspectiva neoliberal donde se mira desde la óptica productiva, en donde los recursos naturales se entienden como capital natural y las personas se toman como capital humano, que junto con la infraestructura se convierten en capital social, los cuales son localizados y evaluados para determinar el potencial endógeno del desarrollo expresado en términos de crecimiento, productividad y competitividad.

18 Referida al principio de justicia territorial o espacial en la provisión, distribución y acceso igualitario y equitativo a bienes, servicios, recursos, transferencias, beneficios y oportunidades. También como garantía de igualdad en la en el tiempo y en el espacio de la población.

f) Crecimiento económico con equidad territorial y con protección social y ambiental $^{19}$.

g) Una activa participación de la población en las decisiones fundamentales del desarrollo ${ }^{20}$, es decir, decidir sobre la forma de vida.

h) La potenciación del ser humano mediante los mecanismos de concienciación (ser consciente del problema de desarrollo) y participación ciudadana (transformación del problema de desarrollo) ${ }^{21}$, para un buen vivir y convivir.

i) Evolución que trae consigo la desaparición de la opresión política,

participación de los pobladores en la creación de las normativas sociales, en los espacios de decisión para elaborar e implementar políticas públicas, en la utilización de espacios públicos y físicos para las prácticas democráticas, la movilización de la ciudanía y su libre expresión. El principio de justicia espacial o territorial rechaza la discriminación, la marginación y la estigmatización en el territorio y propende por el respeto a la vida, la identidad, el arraigo y la dignidad de las personas en este. La polarización geográfica introduce problemas de inequidad territorial. Se inclina por una relación equilibrada entre sociedad, Estado y mercado, en armonía con la naturaleza.

19 En esta visión, el desarrollo sostenible es más que crecimiento; el crecimiento es una condición necesaria para el desarrollo, pero no es suficiente. Reconoce al ser humano como sujeto y fin de la economía, a diferencia de la economía neoliberal, cuyo objeto y fin es el mercado y la competencia. Modelo alternativo de desarrollo de cara al posneoliberalismo.

20 Sobre lo que se debe sostener en cada aspecto de la cuadriga o quadrivium (sociedad, economía, ambiente y lo político-institucional), en el territorio.

21 Proceso que permite a los habitantes utilizar su potencial, adquirir confianza en sí mismos y llevar una vida de dignidad y realización, a la vez que libra a la gente del temor a las carencias y a la explotación. 
económica y social, a la vez que es un movimiento que surge desde la sociedad que está evolucionando o transformando.

j) Un referente universal para la formulación de políticas públicas sostenibles territorializadas y la orientación y ritmo definidos de manera endógena y diferenciada ${ }^{22}$.

k) Actuación para el equilibrio y sostén de las estructuras de la quadrivium a largo plazo ${ }^{23}$.

1) Un proceso de visión global (holístico), dinámico, integral, multidimensional y escalar que en su concepción requiere más que la interdisciplinariedad y la transdisciplinariedad del pensamiento complejo.

m) Una garantía de permanencia en el tiempo y en el espacio que satisface equitativamente las necesidades de la población.

n) Un referente universal para la formulación de políticas públicas compatibles territorializadas, ya que incide en todos los aspectos de la cuadriga: sociales ${ }^{24}$,

22 Por cada sociedad en función de las necesidades, objetivos y particularidades sociales, económicas, ambientales y político-institucionales.

23 No puede estar supeditado a objetivos o visiones de corto plazo.

24 Vivir una vida en paz, larga y sana y favorecer el acceso a los conocimientos. económicos ${ }^{25}$, medioambientales ${ }^{26} \mathrm{e}$ institucionales ${ }^{27}$.

o) La utilización de prácticas cualitativas más que cuantitativas.

\subsubsection{Principios}

Se consideran principios del desarrollo sostenible:

La unidad de la naturaleza (mente-cuerpo y cultura-naturaleza).

a) El diálogo entre las ciencias (socialesnaturales).

b) La ética y la política para la construcción de un modelo de vida sostenible.

c) La expresión territorial de los anteriores reflejada en un paisaje armónico ${ }^{28}$.

d) La planificación y gestión sobre las estructuras ambientales, sociales, económicas e institucionales a largo plazo, en la búsqueda siempre de un buen vivir y convivir para la población.

25 Incrementar la producción y participar equitativamente en el disfrute de sus frutos, para poder llevar una vida decorosa (el crecimiento es condición necesaria para el desarrollo, pero no suficiente)

26 Favorecer un proceso de producción respetuoso con el entorno para legar a las futuras generaciones un planeta en adecuadas condiciones ambientales.

27 Consolidación de la democracia, la libertad y el respeto de los derechos humanos; lucha permanente contra la corrupción y ejercicio pleno del Estado de derecho; prácticas de buen gobierno (concepto que hace referencia a un gobierno democrático, que respeta los derechos humanos y que lucha contra la corrupción).

28 Campo de lectura de las relaciones de poder en equilibrio como paisaje homogéneo. El territorio está ligado al paisaje y no solo tiene que ver con su potencialidad productiva, sino también con la capacidad de provocar una sensación de armonía y bienestar al observador (Ambroise, 2002). 
e) La territorialización de la visión de desarrollo sostenible mediante la implementación de políticas públicas de planificación y ordenamiento territorial.

f) La transparencia, equilibrio, igualdad de oportunidades, responsabilidad, distribución y redistribución de los productos y bienes sociales.

En este sentido, el desarrollo sostenible se entiende como: el equilibrio ${ }^{29}$ de las dimensiones económica, ambiental, sociocultural y político-institucional; de esta manera, se parte de la hipótesis según la cual el desarrollo sólo es sostenible, si cada una de sus dimensiones es sostenible a su interior y en relación con las otras.

\section{Perspectiva geográfica: aportes de la geografía}

Wilbanks (1994, p.1) considera que el desarrollo sostenible se convierte en el desafío que debe ser abordado en el presente por la geografía y que pocas veces una disciplina académica tiene la oportunidad de aportar y contribuir significativamente con sus fundamentos, competencias y saberes reconocidos, a este tema de suma importancia para la humanidad, en su conceptualización, transformación, aplicación, aprendizaje $\mathrm{y}$ toma de decisiones. Concluye que aparece un nuevo horizonte, un nuevo frente de investigación ${ }^{30}$, como algunos

29 Combinación, interacción, armonía, compatibilidad, subsidiariedad, complementariedad y cooperación, entre otras más.

30 Problema emergente derivado de la finitud del planeta, estudiosos lo han llamado: "el de una geografía de las utopías ${ }^{31}$,

La geografía, plantea Wilbanks (1994), puede contribuir para hacer del desarrollo sostenible un verdadero objeto de ciencia, coadyuvando a precisar sus dimensiones espaciales y temporales, lo que constituye un reciente reto para la investigación geográfica.

La propuesta de desarrollo sostenible nace de una producción cultural problémica del espacio en el tiempo. Intenta responder a largo plazo la afectación de estructuras que la sociedad considera en desequilibrio en el tiempo. Esto hace parte del cuerpo epistemológico de la

el sistema económico mundial imperante y la forma social de vida derivada de este como detonante del riesgo de la existencia humana.

31 La utopía ha servido como catalizador de los movimientos sociales que buscan eliminar los desequilibrios y las injusticias en la sociedad, y pretenden alcanzar una sociedad ideal. Para el caso particular se toma como: "un plan de acción hacia nuevos horizontes y rumbos", [...] y una función anticipadora del futuro que ubica a la utopía como horizonte histórico y movilizador de cambios. [...] El pensamiento utópico es filosófico, porque cuenta con un método semejante al método hipotético deductivo, se diferencia del mismo por el uso de la imaginación como una experimentación mental de posibilidades en las que interviene la capacidad imaginativa, en un ejercicio de las posibles ampliaciones de la realidad. La utopía siempre alude a una estructura total del mundo, y es el pensamiento utópico el que la imagina y expresa. La utopía es plan de acción, herramienta teórica, lienzo de mundos imaginarios, primer paso hacia un modo más auténtico de existencia. Plantear una utopía no es soñar despierto, es vivir entre dos mundos, acercándolos, conectándolos. Como intelectuales no podemos resignarnos a reproducir fielmente una tradición que condena el pensamiento crítico y utópico, por considerarlo poco viable para los intereses de un país en 'desarrollo'. Muy por el contrario, pensar es un derecho y un trabajo. En estos tiempos, dar pasos firmes en la búsqueda y construcción de mundos mejores, desde el lugar en el que estemos, es un acto de valentía, y el mejor legado que podemos dejar a las futuras generaciones" (Graffigna, 2009). 
geografía (fundamentos y métodos) y de su investigación aplicada.

El enfoque geográfico es sistémico ${ }^{32}$, integral u holístico, inter y transdisciplinario $^{33}$, y de escala ${ }^{34}$; lo que nutre la concepción del desarrollo sostenible. En su conjunto deja ver que el desarrollo, no es solo crecimiento económico, sino cambios estructurales (económicos, sociales, ecológicos, políticos, institucionales y tecnológicos), que deben colocar en su esencia al hombre como sujeto y objeto histórico de transformación de su entorno, en una dimensión espacial y temporal que incluye interrelaciones de carácter global, regional y local (escalaridad) y de transversalidad entre las distintas dimensiones del sistema en equilibrio en el territorio, si se quiere sea sostenible.

En lo sistémico e integral, se expresa en la articulación de todos los elementos del espacio o territorio en equilibrio y orden en las estructuras territoriales existentes organizadas funcionalmente y que conforman el todo territorial, y no de la suma

32 Este enfoque tiene su máxima expresión en la formulación de modelos, basados en la teoría general de sistemas (1932). La aplicación de este enfoque a las diversas ramas de la geografía se inició después de 1950, introduciendo el concepto sistémico de funcionalidad y complejidad estructural en el territorio.

33 Puede ir más allá de lo interdisciplinar avanzando hacia el pensamiento complejo.

34 La sostenibilidad se estudia y maneja a varios niveles de tiempo y espacio, y en muchos contextos de organización económica, social, ambiental. Se enfoca desde la sostenibilidad total del planeta a la sostenibilidad de sectores económicos, países, municipios, barrios, casas individuales; bienes y servicios, ocupaciones, estilos de vida, etc. En resumen, puede incluir el total de las actividades humanas y biológicas o partes especializadas de ellas (Group of the Millennium Ecosystem Assessment, 2003). de partes. Lo ideal es que dicho orden y equilibrio se manifieste de igual manera en las condiciones sociales, económicas, político institucionales y ambientales justas y equitativas para la existencia en el tiempo. La geografía desde esta óptica aporta a la visión del desarrollo sostenible.

En lo escalar, la geografía coadyuva a crear conceptualmente un sistema categórico del desarrollo sostenible con diferentes características, que de hecho en la realidad opera asi ${ }^{35}$. También contribuye a precisar los objetivos del desarrollo sostenible ${ }^{36}$ en el territorio u espacio específico en cada dimensión de manera jerarquizada ${ }^{37}$, pero integrada ${ }^{38} \mathrm{y}$ a largo plazo.

35 Por ejemplo: a escala regional, un enfoque regionalista contempla estilos de desarrollo diferentes para cada región, con base en el uso de los recursos naturales, la identidad cultural y los sistemas productivos (desarrollo sostenible diferenciado, no en su concepción sino en su operatividad aplicada sobre el interés de una comunidad).

36 En lo ecológico: mantener las características del(os) ecosistema(s) que le son esenciales para la sobrevivencia a largo plazo (especies, poblaciones y ecosistemas). Económico: organizar los sistemas productivos que permitan manejar y gestionar adecuadamente los recursos naturales para que sea atractivo continuar con el sistema económico de interés de la población. Social: distribuir los costos y los beneficios de manera adecuada (equitativa), tanto entre el total de la población actual (equidad intrageneracional) como con la población futura (equidad intergeneracional), se convierte en una obligación. Político institucional: la sostenibilidad de la nación y su tejido social (gobernanza y cohesión social y territorial).

37 A cada escala le corresponde un nivel de la estructura territorial.

38 Relaciones horizontales entre los elementos y estructuras en una misma escala y relaciones verticales de poder entre las estructuras. 
En lo inter y transdisciplinar ${ }^{39}$, convoca las disciplinas; integra los problemas ambientales, económicos, sociales y político-institucionales y colabora en la solución de sus impactos (a corto plazo, acciones coyunturales) y cambios en las estructuras a largo plazo, y avanza hacia el pensamiento complejo en su integralidad.

Además de lo anterior, la geografía ofrece otros tres puntos de vista distintivos para las discusiones y aporte al desarrollo sostenible, como son: la diversidad, los flujos (relaciones o interacciones) y la temporalidad, que a su vez son cualidades también del territorio como las anteriores.

Respecto a la diversidad, los territorios en diferentes escalas y espacios revelan en las dimensiones natural, social, cultural, económica y político institucional sus diferencias ${ }^{40}$ en oportunidades, limitaciones y problemáticas. Son espacios o territorios diversos y en contraste, con

39 La transdisciplinariedad se considera un conocimiento superior emergente, fruto de un movimiento dialéctico de retro-y pro-alimentación del pensamiento, que nos permite cruzar los linderos de diferentes áreas del conocimiento disciplinar y crear imágenes de la realidad más completas, más integradas y, por consiguiente, también más verdaderas. En el campo académico, la fragmentación del saber en múltiples disciplinas no es algo natural sino algo debido a las limitaciones mentales. La toma de conciencia de esta situación implica algo, o mucho, más que una interdisciplinariedad, implica una auténtica transdisciplinariedad o metadisciplinariedad, donde las distintas disciplinas están relacionadas unas con otras y transcendidas, en cuanto la resultante es una cualidad emergente, superior a la suma de sus partes (Martínez, M., 2007).

40 Étnicas, en desarrollo territorial, en dominio territorial, en biodiversidad, en recursos y la explotación de estos, en el nivel de vida, en democracia, en tranquilidad territorial, en transparencia o corrupción, en riesgos y amenazas naturales, etc. condiciones particulares en su organización y funcionamiento.

La geografía, por medio de instrumentos de planificación territorial como la ordenación del territorio, contribuye al desarrollo sostenible en el manejo de la diversidad (particularidades). Como bien lo explica Massiris (2012, p. 28), "la planificación territorial, a diferencia de la planificación global y la sectorial no puede ignorar esta diversidad. En esto radica una de las diferencias esenciales entre la visión sectorial y la territorial de la planificación del desarrollo", para el caso, sostenible.

Respecto a los flujos (relaciones), los geógrafos siempre se han interesado por los flujos en la naturaleza, en la sociedad, entre la naturaleza y la sociedad, entre y dentro de los lugares (interdependencia de los lugares), a lo largo del tiempo. Es evidente que varias preguntas y aspectos relacionados con los flujos son esenciales para la visión del desarrollo sostenible, donde este podría beneficiarse de las perspectivas de la geografía en el caso de los flujos espaciales, económicos, sociales, ambientales y político institucionales. Relacionado con los flujos temporales, los geógrafos pueden ayudar en la comprensión de la dependencia de la trayectoria y la direccionalidad de las dimensiones del desarrollo sostenible a medida que evolucionan en el espacio.

La temporalidad, para la geografía respecto al desarrollo sostenible, involucra el carácter cambiante en el tiempo del territorio. De hecho, al ser el desarrollo 
territorial un constructo social, su concepción varía en función de los cambios económicos, sociales, políticos y culturales que ocurren en el tiempo. Massiris (2012) explica sobre la temporalidad:

Las formas de producción prevalentes en un momento determinado (modelos de desarrollo) y las condiciones de vida de la población, examinadas, se definen en función de las concepciones económicas y estructuras de poder dominantes en dicho momento [...]. La temporalidad del desarrollo territorial nos lleva a pensar que las estructuras territoriales presentes en un momento determinado se explican en función de procesos históricos que son necesarios conocer para entender el porqué de las realidades actuales y sus tendencias de cambio. (p. 28).

Por otra parte, la comprensión geográfica del espacio o territorio presupone el reconocimiento de la espacialidad o configuración espacial de los distintos sistemas que componen la totalidad de lo que existe.

El enfoque geográfico del desarrollo sostenible demanda de la espacialización de las bases, preeminencias o problemas de cada una de las dimensiones que integran el sistema ${ }^{41}$, lo que significa traducirlos

\footnotetext{
41 La espacialidad física expresada en elementos o cualidades de extensión, forma, posición, distancia, movimiento y conexión; la espacialidad biológica u orgánica cuyos elementos son extensión, forma, posición relativa de partes, desplazamiento de fluidos entre los órganos, posibilidades
}

en cuestiones cartografiables que permitan conocer y entender su dimensión territorial, clave para la gestión integral y sostenible del territorio. La aplicación de los sistemas de información geográfica (SIG) es cada día más importante en este sentido, por cuanto promueve la dimensión geográfica del desarrollo sostenible y de igual manera otras herramientas sociales cartográficas que contribuyen al "arte y ciencia" del desarrollo sostenible.

Cuando se piensa en la visualización como un concepto geográfico básico, se reconoce el poder de la comunicación visual en esta era de revolución de la información y de las autopistas de la información. Imágenes visuales, incluyendo la cartografía informática, la fotografía aérea, las imágenes de sensores remotos y fotográficas, y los diagramas espaciales en sistemas de información hipermedia, son cada vez más utilizados para identificar oportunidades, problemas y limitantes en la sostenibilidad de un territorio, y examinar posibles alternativas $^{42}$. Así las correlaciones entre los distintos problemas en las dimensiones del territorio se han agudizado por la evolución de las formas de visualización de la información, como formas efectivas para mostrar las consecuencias de diferentes cursos de acción que impactan el territorio y su sostenibilidad.

de movimiento como conjunto, etc. La espacialidad social basada en la articulación entre naturaleza y sociedad, pero con las leyes sociales sobreconstruyendo la espacialidad natural (Coraggio, 1994).

42 El uso de las imágenes está basado en la tradición de trabajo de campo del geógrafo, que une la profusión de datos secundarios y las imágenes, a los datos primarios de la observación y experiencia personal. 
La dimensión geográfica del desarrollo sostenible contribuye y lo asiste en la concepción de su visión, por cuanto propende por la concreción del equilibrio y complementariedad territorial en las dimensiones mencionadas (Quadrivium del desarrollo sostenible), mediante la territorialización de las políticas públicas de planificación y ordenamiento territorial $^{43}$. Aquí la geografía ayuda a responder preguntas en cada dimensión del territorio en relación con su sostenibilidad, tales como: ¿Qué es necesario sostener en lo ambiental, en la sociedad, en lo económico, en lo político institucional?, ¿es viable sostener un sistema?, ¿qué es sostenible en la estructura?, entre otras más.

Todas las cualidades examinadas anteriormente involucran la noción de territorio como "síntesis de las relaciones que los grupos sociales establecen con los espacios que ocupan para satisfacer sus necesidades" (Raffestin, 1986, citado por Herrero, 2009, p. 275). Se trata de relaciones tanto funcionales ${ }^{44}$ como afectivas o identitarias ${ }^{45}$, es decir, dos dimensiones territoriales, una material y otra simbólica.

Respecto a lo simbólico, la geografía desde su raciocinio crítico del territorio

43 Desarrollo armónico de los distintos sistemas o dimensiones espaciales, atenuando las disparidades y disfuncionalidades del territorio, además de promover sus potencialidades y limitar las vulnerabilidades.

44 Uso y ocupación que los grupos sociales dan al espacio geográfico, materializadas en un orden territorial cambiante en el tiempo (Herrero, 2009).

45 Relaciones afectivas que ligan a las personas y grupos con el territorio, las cuales hacen parte de la cultura espiritual de las poblaciones (Herrero, 2009). propende por el rescate de lo cultural en cuanto a identidad, arraigo y pertenencia a este, lo que es fundamental y vital para el desarrollo sostenible.

Otro papel importante de la geografía en el siglo XXI respecto al desarrollo sostenible, es el de la necesidad urgente de $d e-$ finir y comprender el territorio nacional, regional y local real, desmitificando los emblemas de la modernidad (el país más rico, biodiverso, el patrimonio de América, la Atenas suramericana, el orgullo de América, la democracia más perfecta de América, etc.); ¿cuál es la realidad? cuál es el estado actual de patrimonio?, ¿cuál es nuestra diversidad?, ¿cuál es la sostenibilidad de la nación ${ }^{46}$ (gobernanza y cohesión social y territorial)?, ¿cómo vivimos?, etc.

La geografía lleva implícita en su concepción y definición la incorporación del espacio o territorio como sustrato del accionar de las personas. El desarrollo sostenible como visión del constructo social debe ser territorializado o concomitantemente "geografizado", para que los componentes naturales, sociales, económicos, políticos e institucionales articulados y ordenados, en su conjunto puedan, por medio de sus estructuras en el tiempo y en equilibrio garantizar la supervivencia de las personas.

\footnotetext{
46 Un país no es sostenible cuando hay pobreza, conflicto armado, desplazados, delincuencia, violencia, inequidad, brechas sociales, discriminación o exclusión, concentración en la riqueza y distribución de la tenencia de la tierra, ilegalidad e ilegitimidad, entre otros.
} 
De esta manera, la importancia de la geografía en la visión del desarrollo sostenible radica en su capacidad de concretarlo en el territorio (organización espacial), lo que involucra la idea fundamental de equilibrio territorial.

\subsection{Equilibrio territorial}

El equilibrio territorial ${ }^{47}$ está directamente relacionado en la dimensión social con la equidad y la justicia, social y territorial; en la cultural, con la identidad, el arraigo y la pertenencia territorial; en la económica, con la igualdad social y territorial; en la ambiental, con la sostenibilidad y armonía ambiental territorial; y en la dimensión político institucional, con la gobernabilidad y la cohesión social y territorial (Figura 1). Los desequilibrios territoriales son precisamente las desigualdades en dichas dimensiones espaciales inaceptables que afectan las estructuras territoriales.

El término está referido a la búsqueda y concreción permanente de un desarrollo territorial en equilibrio, por medio de las diferentes dimensiones del espacio o territorio, al interior de cada dimensión y entre estas (estructuras) y entre los diferentes componentes objetivo (Tabla 1) para el logro del desarrollo sostenible, en procura de un buen vivir y convivir para

$47 \quad$ Es más frecuente la utilización negativa del término desequilibrio territorial. "Si la necesidad de combatir los desequilibrios resulta un propósito loable, la de conseguir un mayor equilibrio territorial parece más discutible, lo que explica el uso más frecuente de la locución negativa. [...] Este concepto requiere definir a qué hechos se atribuyen significados de desigualdad y a qué escalas o ámbitos de la organización territorial (Zoido et al., 2000). la población. Así, mediante el concepto de equilibrio territorial se busca corregir los actuales desequilibrios espaciales (desajustes territoriales) al interior de las estructuras en las dimensiones en mención y entre estas, producidas en el marco de un modelo económico, para el caso neoliberal.

\begin{abstract}
Visto así, el desarrollo territorial se manifiesta en el equilibrio $u$ orden de las estructuras territoriales existentes, cuya valoración dependerá de la concepción, filosofía o ideología bajo la cual se interprete. Lo deseable es que dicho orden exprese condiciones sociales, económicas, políticas y administrativas justas para todos los seres humanos y territorios, así como condiciones ambientales propicias para la existencia saludable de todos los seres vivos por igual, sin discriminaciones ni exclusiones (Massiris, 2012, p. 27).
\end{abstract}

\section{Conclusiones}

Pasaron más de 75 años desde que Schumpeter (1935) introdujo en el mundo académico y político el tema del desarrollo como objeto de trabajo, en su libro titulado El Análisis Económico, que luego fue utilizado por el presidente norteamericano Harry S. Truman en su discurso ante las Naciones Unidas en 1949 y desde entonces se continúa con la tarea de salir del subdesarrollo con la visión occidental, sin lograrlo. 
Los procesos de desarrollo en la aplicación de la visión económica occidental establecen que el crecimiento es una condición necesaria, pero no suficiente para el desarrollo. Lo anterior abre paso a la idea que el desarrollo es un proceso integral y que su concepción requiere de una visión global. Por otra parte, desde el ambientalismo se demuestra la finitud de los recursos naturales, junto con el agravamiento de los problemas ambientales.

Por tanto, el develar, resignificar y deconstruir el discurso del desarrollo y su presunción de universalidad, como parte de la reinterpretación de la modernidad, se convierte en un ejercicio fundamental para dejar atrás los esquemas mentales del desarrollismo colonial en la construcción de la visión territorial sostenible para un buen vivir y convivir.

El modelo de desarrollo se considera básicamente como una construcción social, y que como tal es posible deshacerlo, deconstruirlo y por tanto reconstruirlo o repensarlo de manera diferente.

La geografía, como disciplina académica, tiene la oportunidad de aportar a este tema con sus fundamentos, enfoques, competencias y saberes reconocidos, en la visión de una nueva forma de entender la vida.

La visión territorial sostenible supera la perspectiva economicista o productivista del desarrollo expresada en concepción limitada del crecimiento económico y la conservación o preservación del medio ambiente y los recursos naturales, por cuanto la noción de sostenibilidad involucra estructuralmente, además de los sistemas económico y ambiental, el social, cultural y político institucional.

Esta visión no comparte la concepción de la "sostenibilidad del crecimiento económico" o de la llamada "sostenibilidad clorofila", concepciones actuales que priman en el desarrollo, la planeación y el ordenamiento territorial y que están subordinadas al modelo de desarrollo económico neoliberal.

Tampoco mira el desarrollo exclusivamente desde la orilla ambiental de la conservación prescindiendo de la sociedad, ni en la pugna economía-ambiente, por cuanto en la lógica del capital entre más crecimiento económico, más crece la explotación de los recursos, más rápido se hace sentir la finitud de la naturaleza y más problemas sociales se generan.

En lo cultural no impulsa el modelo de desarrollo hegemónico monocultural y globalizador de Occidente en una posmodernidad en clave consumista, y en lo alternativo, el purismo de la descolonización cultural que significa volver al statu quo ante o ideal de las culturas no contaminadas exclusivamente a partir del Abya Yala ${ }^{48}$, en territorios de interculturalidad $^{49}$.

48 Nombre que se utiliza desde el mundo indígena para referirse al continente americano por el pueblo Tule-Kuna del oriente de Panamá y occidente de Colombia, antes de la llegada de Cristóbal Colón y los europeos. Literalmente significa tierra en plena madurez o tierra de sangre vital (López, 2004).

49 La cultura es resultado de un proceso de inter-transculturación. "Este término resalta la dialéctica espacial y temporal entre 'culturas' : una cultura actual concreta resulta 
Desde lo político-institucional no defiende y apuntala la visión dominante occidental que nos conduce al "desarrollo del sub-desarrollo" como reflejo de la colonialidad y neo-colonización que implica además de la hegemonía económica, una ocupación simbólica y mediática, anatopismo50, subalteridad51 y una alineación cada vez más sutil.

En lo territorial considera que no es posible concebir el desarrollo sostenible sin equilibrio en las estructuras dimensionales que lo integran.

Desde este punto de vista se puede concluir que las sociedades con enormes y crecientes contradicciones económicas, ambientales, sociales, culturales y político institucionales son insostenibles y los "arreglos" que se desarrollen dentro de este marco, lo serán también. de múltiples procesos de enriquecimiento mutuo entre tradiciones distintas (inter) y de transformaciones históricas (trans) en el seno de una misma cultural" (Estermann, 2009, p. 5).

50 Estermann (2003, p. 2) escribe que Victor Andrés Belaúnde (1889-1966) acuñó en sus "Meditaciones Peruanas" el término "anatopismo" para resaltar el carácter des-contextualizado del pensamiento latinoamericano que simplemente "trasplanta" la filosofía occidental al suelo (topos) americano, sin tomar en cuenta la propia realidad y el contexto específico de América Latina.

51 Proceso de colonización en Latinoamérica por parte de los europeos en el que se impone una cultura sobre la otra, sin tratar de entender sus creencias o forma de vida y que al ser diferente debe ser transformada. Tal lectura colonizadora ha generado hasta nuestros días, exclusión social y la constante eliminación de las ideas culturales que sean diferentes de las de los colonizadores. 


\section{Literatura citada}

Ambroise, R. (2002). Paisaje y agricultura: Un proyecto nuevo. En Paisaje y ordenación del territorio. (p. 230-236). Sevilla, España: Consejería de Obras Públicas y Trasporte, Fundación Duque Soria,

Ardila calderón, G. (2011). Interrelaciones entre historia, cultura y medio ambiente. Ponencia. Congreso de Ciencias y Tecnologías Ambientales. Universidad Santo Tomás, Tunja, Boyacá, Colombia.

Bury, J. (1971). La idea de progreso. Madrid, España: Alianza.

Coraggio, J. L. (1994). Territorios en transición. Crítica a la planificación regional en América Latina (3ra. Ed.). México, Toluca: Universidad Autónoma del Estado de México, Instituto Literario No. 100.

Escobar, A. (1994). Desarrollo sostenible diálogos de discursos. En Integración y equidad: democracia, desarrollo y política social. Bogotá, Colombia: Viva la Ciudadanía, Tercer Mundo.

Escobar, A. (2007). La invención del Tercer Mundo. Serie Colonialidad-modernidad-descolonialidad. Caracas, Venezuela: El Perro y la Rana.

Estermann, J. (2003). Anatopismo como alienación cultural. Culturas dominantes y dominadas en el ámbito andino de América Latina. En R. Fornet-Betancourt (ed.). Culturas y poder: interacción y asimetría entre las culturas en el contexto de la globalización. (177-202). Bilbao: Desclée de Brouwer.

Estermann, J. (2009). Colonialidad, descolonización e interculturalidad. Apuntes desde la filosofía intercultural. En Interculturalidad Crítica y Descolonización. Fundamentos para el Debate. (51-70). La Paz, Bolivia: Instituto Internacional de Integración, Convenio Andrés Bello (III-CAB).

González, F. (2006). En busca de caminos para la comprensión de la problemática ambiental (La escisión moderna entre cultura y naturaleza). Revista Ambiente y Desarrollo. Ensayos V. Bogotá, Colombia: Pontificia Universidad Javeriana, Facultad de Estudios Ambientales y Rurales, Instituto de Estudios Ambientales para el Desarrollo (IDEADE), Javegraf.

González, F. \& Galindo, M. (1999). Dimensión ético política para el uso y valoración de la biodiversidad. Bogotá: Universidad Javeriana, Instituto de Estudios Ambientales para el Desarrollo (IDEADE).

Graffigna, C. (2009). ¿Utopía? Recuperado de http://lageografiaweb.blogspot.com/2009/07/ utopia.html 
Group of the Millennium Ecosystem Assessment. (2003). Chapter 5. Dealing with Scale. Ecosystems and Human Well-being. Conceptual Framework Working. (pp. 107124). London: Island Press.

Gutiérrez, F. et al. (2004). Perfiles urbanos en la Amazonia colombiana. Bogotá, Colombia: Instituto Amazónico de Investigaciones Científicas Sinchi. Programa de Asentamientos Humanos. Recuperado dehttp://sinchi.org.co/index.php?option =com_k2 $\&$ view $=$ item \&id $=242: \&$ Itemid $=1924$

Gutiérrez, F. (2010). Desarrollo sostenible en Colombia: utopía o realidad. Bogotá, Colombia: Convenio Universidad Pedagógica y Tecnológica de Colombia (UPTC), Programa de Doctorado en Geografía, Tesis Doctoral (en edición).

Herrero, M. (2009). La dimensión material y simbólica de los conflictos territoriales. Una perspectiva para la gobernabilidad de los territorios. En J. Farinos, J. Romero \& J. Salom (ed.). Cohesión e inteligencia territorial. Dinámicas y procesos para una mejor planificación y toma de decisiones. Colección Desarrollo territorial. Serie Estudios y Documentos 7. (p. 265-290). Valencia, España: Universidad de Valencia.

Kuhn, T. S. (1982). Las estructuras de las revoluciones científicas. México: Fondo de Cultura Económica.

López, M. A. (2004). Encuentros de los Senderos de Abya Yala. (1 ${ }^{\text {a }}$ ed.). Quito, Ecuador: s.n.

Martínez, M. (2007). Conceptualización de la transdisciplinariedad. Línea de investigación epistemología y metodología cualitativa. Caracas, Venezuela: Universidad Simón Bolívar de Caracas.

Martínez, P. M. (2005, 9-12 de noviembre). Ordenamiento territorial y desarrollo sostenible. Memorias. II Encuentro de Hábitat Sostenible. BIOCASA, CAMACOL, Universidad del Valle, Departamento de Geografía, Cali, Colombia.

Massiris, A. (2012). Gestión territorial y desarrollo: hacia una política de desarrollo territorial sostenible en América Latina. Tunja, Boyacá, Colombia: Grupo Imprenta y Publicaciones Universidad Pedagógica y Tecnológica de Colombia (UPTC).

Méndez, R. (1988). El espacio de la geografía humana. En R. Puyol, J. Estébanez \& Méndez, R. Geografía Humana. (p. 9-50). Madrid, España: Cátedra.

Múnera, M. C. (2007). Resignificar el desarrollo. Medellín, Colombia: Universidad Nacional de Colombia, Facultad de Arquitectura, Sede Medellín, Escuela del Hábitat (CEHAP). 
Porto-Gonçalves, C. W. (2009). De saberes y de territorios: diversidad y emancipación a partir de la experiencia latinoamericana. A. Elizalde (trad.). Revista Poli, 8 (22), 121-136. Caracas, Venezuela: Universidad Bolivariana.

Huanacuni, f. (2010, febrero). Buen vivir/vivir bien. Filosofía, políticas, estrategias y experiencias regionales andinas (1ra ed.) Lima, Perú: Coordinadora Andina de Organizaciones Indígenas (CAOI).

Ivonne, H. \& Vasapollo, L. (2011, febrero). Vivir bien ¿paradigma no capitalista? (1 ra ed. en español). La Paz, Bolivia: Convenio Postgrado en Ciencias del Desarrollo de la Universidad Mayor de San Andrés (CIDES-UMSA) y el Departamento de Economía de la Universidad de Roma "La Sapienza".

Sachs, W. (1996). Anatomía política del desarrollo sostenible. En La gallina de los huevos de oro. Un debate sobre el concepto de desarrollo sostenible. Bogotá, Colombia: Cerec.

Serres, M. (1991). El contrato natural. U. Larraceleta \& J. Vázquez (trad.). Valencia, España: Pre-textos.

Sunkel, O. \& Paz, P. (1971). El subdesarrollo latinoamericano y la teoría del desarrollo. México: Siglo XXI.

Wilbanks, J. T. (1994). Presidential Address Sustainable Development in Geographic Perspective. Oak Ridge National Laboratory. Cambrige, Oxford, UK. Annals of the Association of American Geographers, 84(4), 541-556.

Zoido, F., De La Vega, Sofía, Morales, G., Mas, R. \& Lois, R. C. (GRUPO ADUAR). (2000). Diccionario de geografía urbana, urbanismo y ordenación del territorio. Barcelona, España: Ariel.

Recepción: 12 de marzo de 2012

Evaluación: 7 de mayo de 2012

Aprobación: 10 de julio de 2012 
